\title{
Complete Atelectasis of the Left Lung from Anaplastic Large-Cell Lymphoma
}

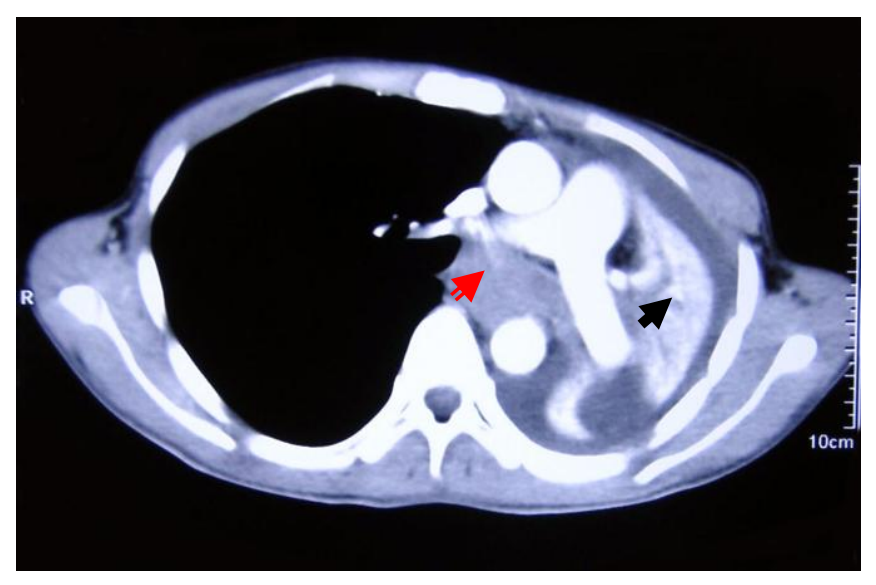

FIGURE 1. A contrast-enhanced CT scan shows a mass (red arrow) in the middle mediastinum compressing the left main bronchus, resulting in a complete atelectasis of the left lung (black arrow) and a mediastinal shift toward the left. A pleural effusion is visualized.

\author{
Liling Zhang and Gang Wu* \\ Cancer Center, Union Hospital, Tongji Medical College, Huazhong University of \\ Science and Technology, Wuhan, China \\ E-mail:wg1893@hotmail.com
}

Received May 12, 2010; Revised June 14, 2010; Accepted June 15, 2010; Published July 6, 2010

KEYWORDS: pulmonary atelectasis, anaplastic large-cell lymphoma, computed tomography, radiotherapy

Acute, complete, pulmonary atelectasis due to intrinsic or extrinsic bronchial obstruction could result in severe dyspnea. An emergency medical intervention should be done promptly on the basis of an accurate diagnosis.

The images we present here are from an 18-year-old boy with severe dyspnea, palpitation, dry cough, and fever for 4 days. Oxygen saturation measured by a pulse oximetry was $80 \%$. Physical examination revealed a 3- $\times 3-\mathrm{cm}$ firm mass in his right neck. Chest computed tomography $(\mathrm{CT})$ demonstrated a mass $(5.4 \times 3.5 \times 5 \mathrm{~cm})$ in the middle mediastinum compressing the left main bronchus, resulting in a complete atelectasis of the left lung and a mediastinal shift toward the left (Fig. 1). A left pleural effusion was also presented. A biopsy diagnosed an anaplastic lymphoma kinase (ALK)-positive anaplastic large-cell 
lymphoma (ALCL) and confirmed the CT findings. A palliative radiotherapy of total $15 \mathrm{~Gy}$ in five fractions was delivered from the 1st day of administration. The symptoms were totally resolved after 3 days of radiotherapy, and oxygen saturation level returned to normal. Subsequent chest CT showed the mass had almost completely disappeared with re-expansion of the left lung and return of the mediastinum to the midline, as well as the disappearance of pleural effusion (Fig. 2). The patient then underwent a combination chemotherapy regimen comprising CHOP (cyclophosphamide, adriamycin, vincristine, prednisone).

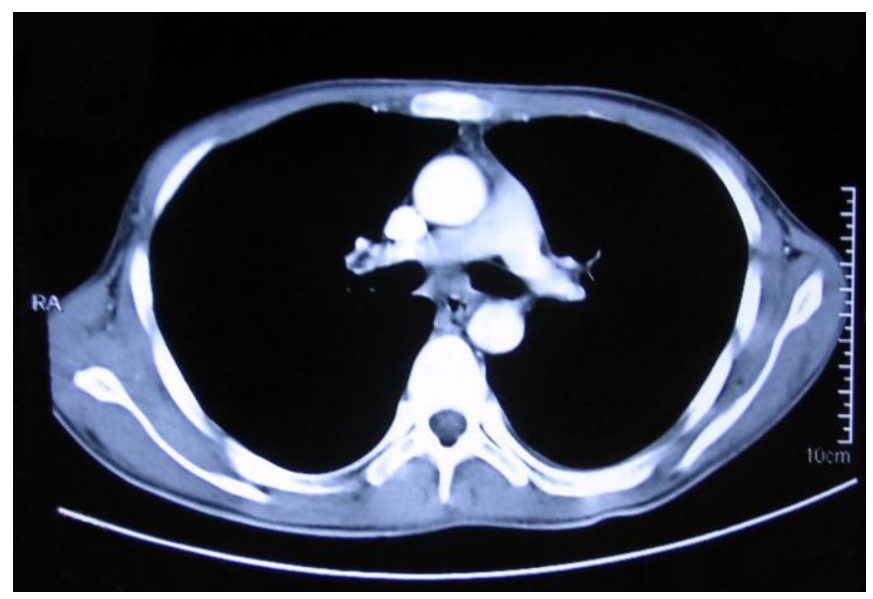

FIGURE 2. Chest CT on the 5th day of radiotherapy shows re-expansion of the left lung with and return of the mediastinum to the midline. The mass is nearly completely disappeared.

ALCL involving the mediastinum is not common. Differential diagnosis includes nodular sclerosing Hodgkin's lymphoma, large B-cell lymphoma, and lymphoblastic lymphoma, which are the three most common types of mediastinal lymphoma[1]. Biopsy and immunohistochemistry are helpful to make a definitive diagnosis. Once histology is known, radio- or chemotherapy could be performed promptly to resolve the complete atelectasis due to extrinsic compressing of the main bronchus by malignant lymphoma[2]. As in reports, cardiopulmonary bypass, Nd:YAG laser, and temporary airway stenting might also be useful in the management of symptomatic airway stenoses[3,4].

\section{REFERENCES}

1. Duwe, B.V., Sterman, D.H., and Musani, A.L. (2005) Tumors of the mediastinum. Chest 128, $2893-2909$.

2. Weidmann, E., Gramatzki, M., Wihelm, M., and Mitrou, P.S. (2004) Diagnosis and actual therapy strategies in peripheral T-cell lymphomas: summary of an international meeting. Ann. Oncol. 15, 369-374.

3. Schmidt, B., Massenkeil, G., John, M., Arnold, R., and Witt, C. (1999) Temporary tracheobronchial stenting in malignant lymphoma. Ann. Thorac. Surg. 67, 1448-1450.

4. Shimokawa, S., Watanabe, S., and Niwatsukino, H. (2000) Endobronchial infiltration of malignant lymphoma. Ann. Thorac. Surg. 69, 1985.

\section{This article should be cited as follows:}

Zhang, L. and Wu, G. (2010) Complete atelectasis of the left lung from anaplastic large-cell lymphoma. TheScientificWorldJOURNAL 10, 1332-1333. DOI 10.1100/tsw.2010.140. 


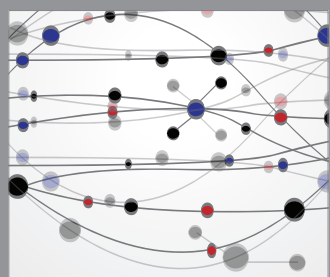

The Scientific World Journal
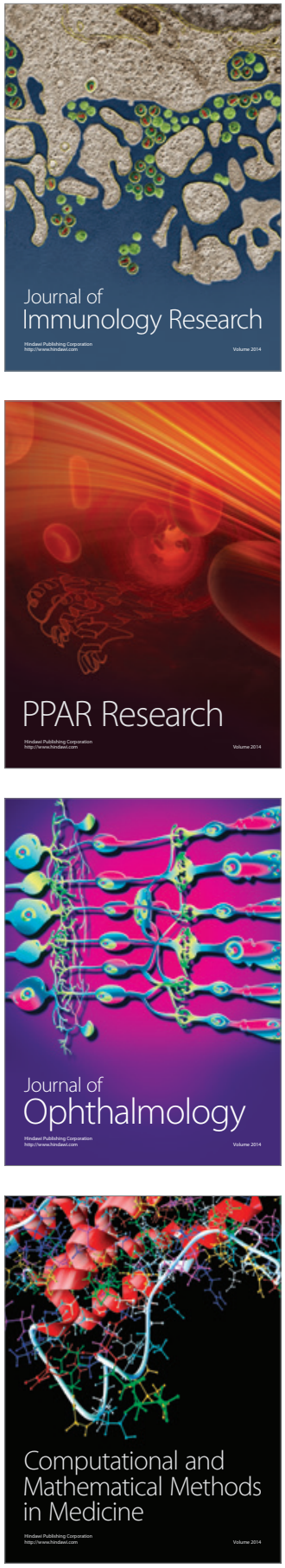

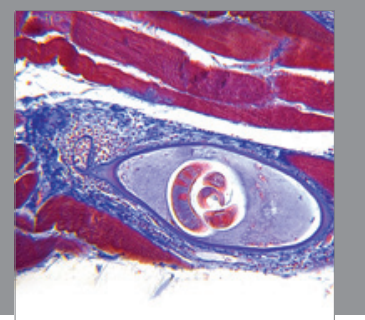

Gastroenterology

Research and Practice
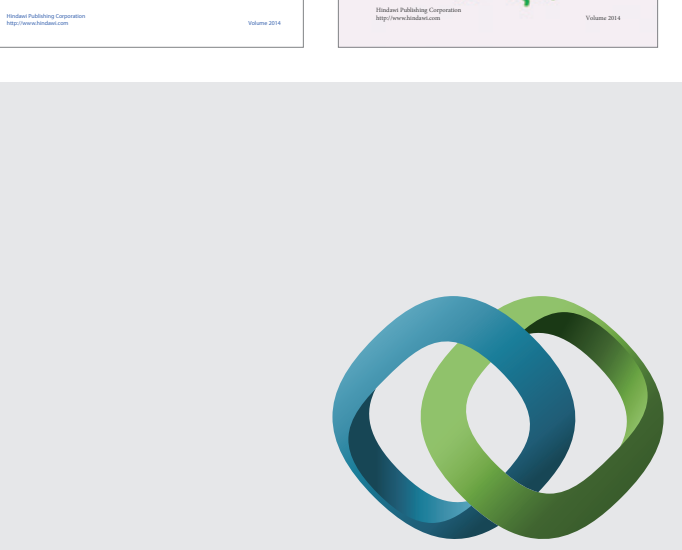

\section{Hindawi}

Submit your manuscripts at

http://www.hindawi.com
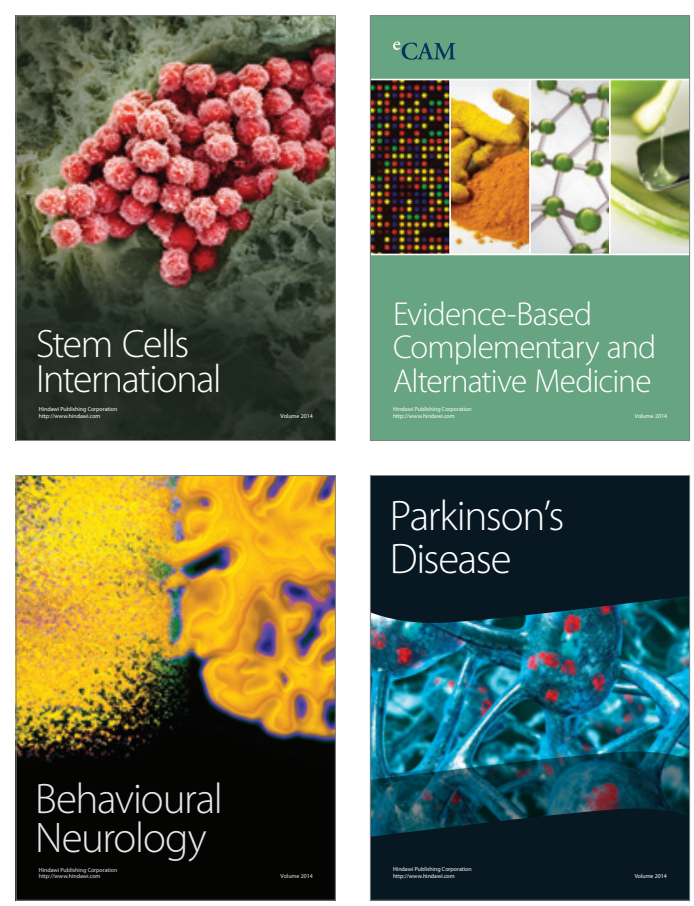

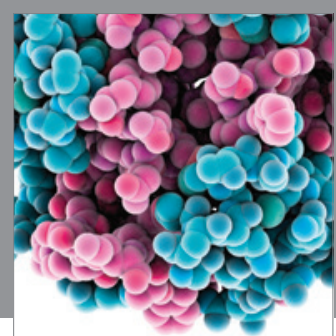

Journal of
Diabetes Research

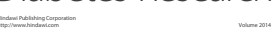

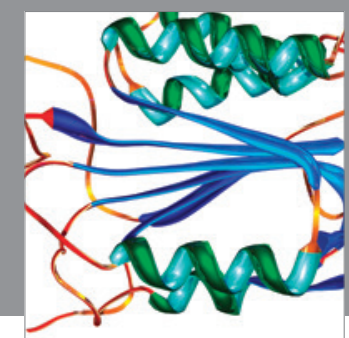

Disease Markers
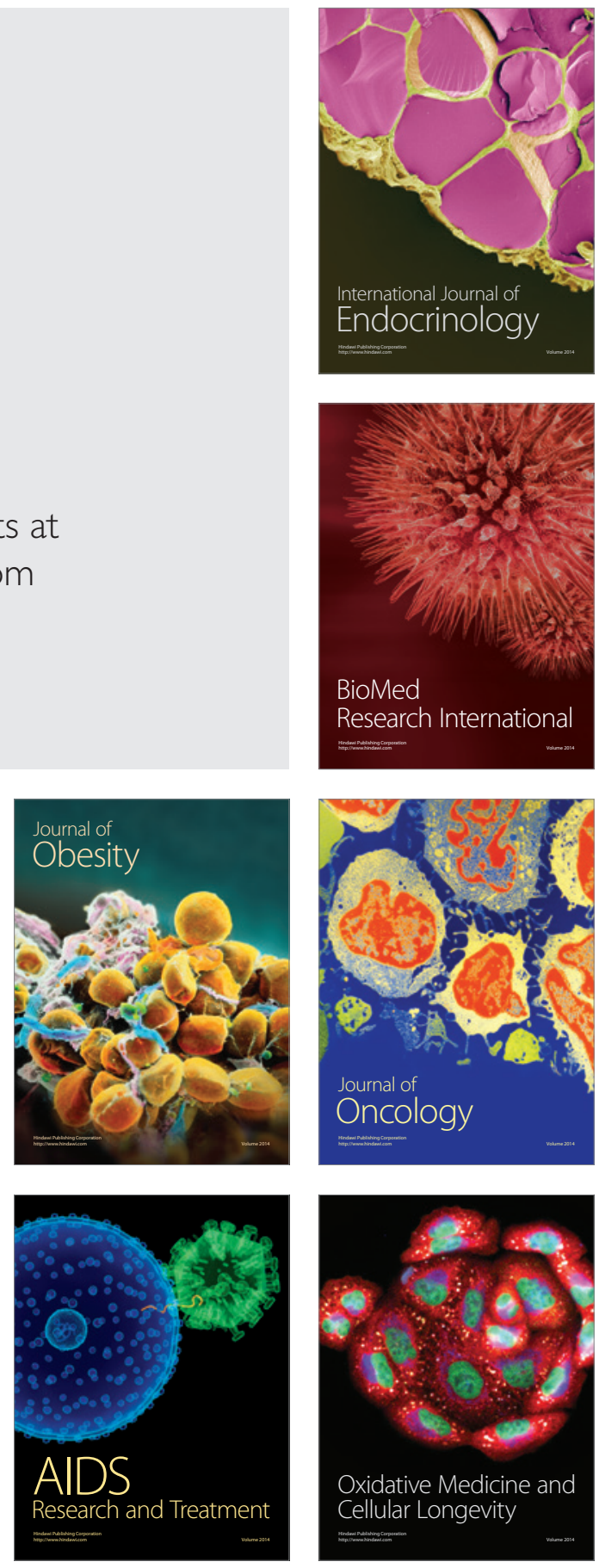